\title{
Avaliação da arborização urbana do bairro Jardim Primavera, no município de Salto de Pirapora - SP.
}

\author{
Felipe Coelho de Souza Petean ${ }^{1}$ \\ Francisco Carlos Adriano Júnior ${ }^{1}$ \\ Kelly Cristina Tonello ${ }^{2}$ \\ Mariana Pires Franco ${ }^{1}$ \\ José Mauro Santana da Silva ${ }^{2}$ \\ Juliano Gil Nunes Wendt ${ }^{2}$ \\ Luiz Carlos de Faria ${ }^{2}$
}

\author{
${ }^{1}$ Universidade Federal de São Carlos campus Sorocaba \\ Rodovia João Leme dos Santos, Km 110, Bairro Itinga, Sorocaba - SP, 18052-780 \\ coelho.petean@gmail.com, francisco_sliver@hotmail.com, ma.pires@hotmail.com \\ ${ }^{2}$ Prof. Eng. Florestal, Universidade Federal de São Carlos campus Sorocaba \\ Rodovia João Leme dos Santos, Km 110, Bairro Itinga, Sorocaba - SP, 18052-780 \\ kellytonello@ufscar.br, faria.lc@gmail.com,wendt@ufscar.br, josemauro@ufscar.br
}

\begin{abstract}
The present work was conducted to evaluate and implement the urban forestry in the Jardim Primavera neighborhood, in Salto de Pirapora city, state of Sao Paulo. In order to meet State Laws, that request a municipal Green Area Index (IAV) of $12 \mathrm{~m}^{2}$ per inhabitant, and promote life quality, Salto de Pirapora city adopted an IAV of $25 \mathrm{~m}^{2}$ per inhabitant. Due this end, the IAV was estimated by adding the tree tops circumferences $(12,219.23$ $\mathrm{m}^{2}$ ) and dividing by the number of the neighborhood inhabitants, using the ArcGis ${ }^{\circledR}$ software. The green area index found was $8.1 \mathrm{~m}^{2}$ per inhabitant. A number of 195 trees were indicated to increase the neighborhood IAV. As a second step, a water spring in the nearby will be reforested in order to enrich the local flora and grant the municipal IAV into $25 \mathrm{~m}^{2}$.
\end{abstract}

Palavras-chave: urban forestry, green área índex, restouration.

\section{Introdução}

O homem sempre teve uma relação de dependência com as árvores. Desde o início das civilizações, o ser humano busca nas florestas matéria prima para os mais diversos fins, seja para construção civil ou como fonte de energia.

Em meados do século passado, o país passou por uma intensa onda de industrialização, implicando numa perda gradativa da qualidade das áreas verdes dos municípios, principalmente daqueles que experimentaram o boom da industrialização nas décadas de 1970 e 1980 (Coporusso e Matias, 2008).

A maioria dos municípios brasileiros cresceu sem planejamento e sem a criação de ambientes que contribuíssem com o bem-estar dos cidadãos, sejam praças, parques urbanos ou a arborização urbana. O que se vê quando se viaja pelo interior do Estado de São Paulo, por exemplo, o que se vê são cidades com calçadas concretadas, sem árvores, gerando um desequilíbrio climático, aumentando a temperatura nos centros urbanos, resultando numa paisagem árida, que não propicia uma condição saudável de vida.

Nas cidades, as árvores assumem um papel que gera reflexos positivos e imediatos aos munícipes. Um ambiente urbano devidamente arborizado produz efeitos diretos e indiretos. A exemplo de efeitos diretos tem-se, por exemplo que, as árvores urbanas servem como ilhas naturais de diversidade, servindo como fonte de sombra, alimento e lazer. A arborização urbana é planejada, entre outros fins, para promover o equilíbrio térmico nos centros urbanos, 
a diminuição do consumo de energia, o resfriamento por sombreamento e evapotranspiração, melhoria da qualidade do ar, controle de inundações, proteção contra ventos, controle da poluição sonora, promoção da biodiversidade local, melhoria da paisagem e controle lumínico (Sbau, 2004). Como efeitos indiretos pode-se citar: a sensibilização da população, a qual passa a criar uma responsabilidade ambiental, fortalecimento da organização comunitária bem como uma valorização dos bairros.

A fim de ampliar as áreas verdes arborizadas urbanas, o Governo do Estado de São Paulo aprovou no dia 24 de Julho de 2009, a Lei no 13.580/2009, que defende um Índice de Áreas Verdes (IVA) de $12 \mathrm{~m}^{2}$ por habitante, servindo assim, como parâmetro para os municípios paulistas seguirem e planejarem atividades que contemplassem a arborização urbana (São Paulo (estado), 2009). No entanto, a plantio precisa ser bem planejado, levando em conta as condições espaciais e os espaços abertos da cidade para que a qualidade que se deseja alcançar com a arborização urbana seja plena.

Numa adequação á Lei no 13.580/2009, o Município de Salto de Pirapora propôs um IAV de $25 \mathrm{~m}^{2}$, o que estimula a conservação da biodiversidade local e promove o conforto térmico e visual da cidade.

Sendo assim, o presente trabalho teve por objetivo realizar o diagnóstico preliminar da situação atual da arborização urbana do bairro piloto Jardim Primavera no município paulista de Salto de Pirapora, e apresentação de enriquecimento e melhoria da mesma.

\section{Metodologia}

\subsection{Caracterização do local}

O Município de Salto de Pirapora está localizado na bacia hidrográfica do SorocabaMédio Tietê (UGRH 10), na região administrativa de Sorocaba, a $120 \mathrm{~km}$ da capital paulista. Salto de Pirapora está a 630 metros do nível do mar, na latitude 23³8'56" S e a uma longitude de $47^{\circ} 34^{\prime} 24^{\prime \prime} \mathrm{W}$. De acordo com o último levantamento populacional feito pelo Ibge, o municipio possui 37.324 habitantes, e sua área é aproximadamente $280 \mathrm{Km}^{2}$ (Ibge, 2009).

\subsection{Caracterização do bairro piloto Jardim Primavera}

O bairro Jardim Primavera (Figura 1) se localiza próximo ao centro da cidade, compreendido entre as ruas Graciliano A. Souza, Avenida Carlos Chagas e rua Romeu Marcello. Segundo último censo municipal, o bairro possui 1.511 habitantes. 


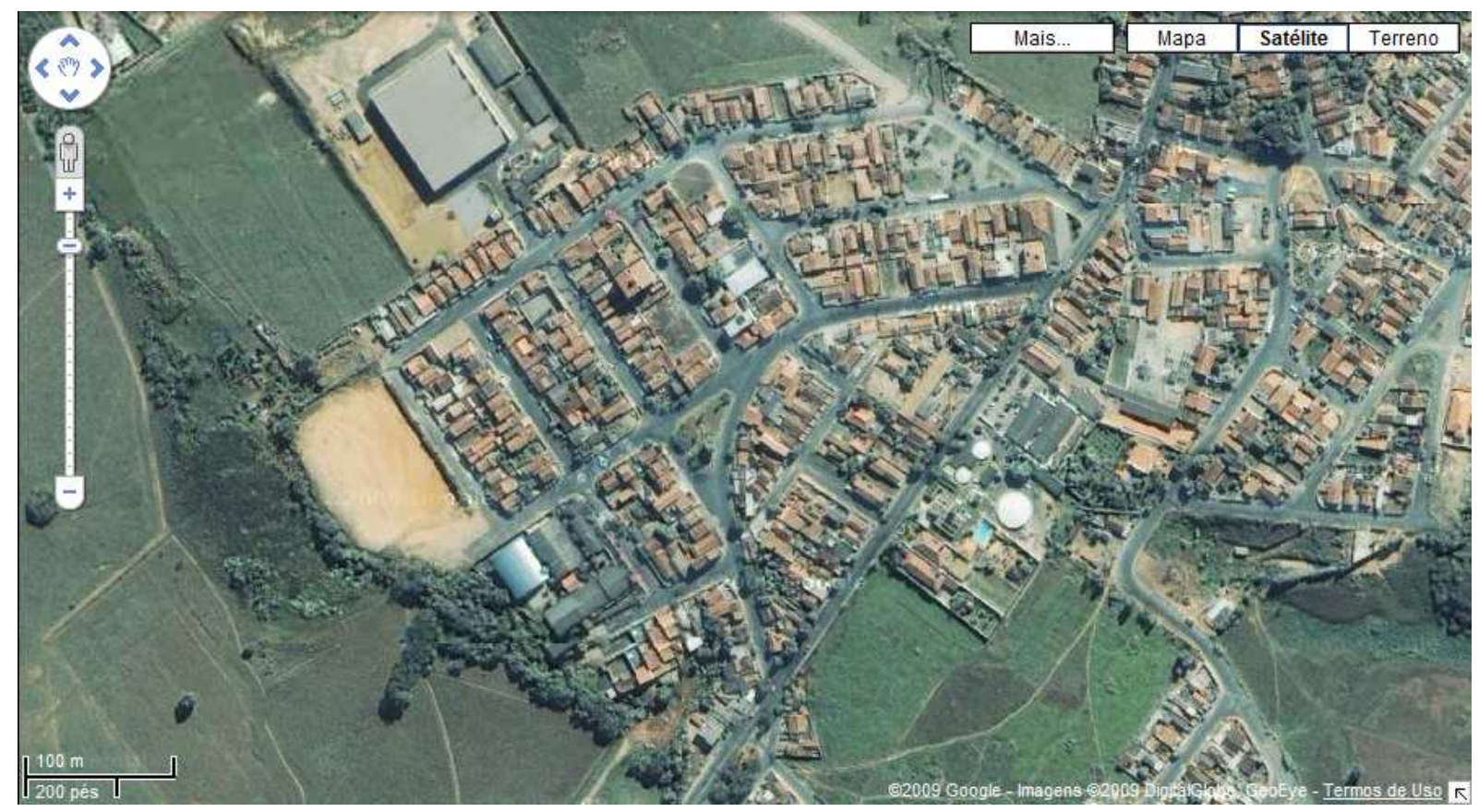

Figura 1. Fotografia via satélite do bairro piloto Jardim Primavera, localizado em Salto de Pirapora, São Paulo.

\subsection{Levantamento arbóreo urbano}

O levantamento das espécies florestais arbóreas presentes no bairro Jardim Primavera foi realizado in loco, ao longo do mês de julho e agosto de 2009. Para isso, quantificou-se os indivíduos arbóreos e analisou-se a fitossanidade dos mesmos. Com base nesses dados, foram sugeridas espécies de acordo com a largura da calçada e fiação elétrica.

\subsection{Cálculo do IAV}

O Índice de Área Verde do bairro piloto Jardim Primavera foi calculado dividindo-se o somatório das áreas verdes (indivíduos arbóreos) do bairro, inclusive a mata circundante da nascente do córrego do Jardim Primavera, pelo seu número de habitantes. O somatório foi feito por meio de fotos aéreas e auxílio do software ArcGis ${ }^{\circledR}$ versão 9.2., obtendo-se o valor de $12.210,23 \mathrm{~m}^{2}$ de área verde. Dividindo-se este valor pelo número de habitantes do bairro, chegou-se ao valor aproximado de $8,1 \mathrm{~m}^{2}$ de área verde por habitante do Jardim Primavera.

\section{Propostas de implantação da arborização urbana}

Com base no diagnóstico preliminar da situação atual da arborização urbana do Jardim Primavera, as seguintes atividades são propostas:

\subsection{Listagem de espécies}

Ao percorrer todo bairro, verificou-se a possibilidade de enriquecimento da arborização do mesmo em diversos pontos. A listagem da quantidade de mudas arbóreas que podem ser inseridas por rua do bairro Jardim Primavera pode ser visualizada no Quadro 1. A rua Raimundo da Rosa foi a que apresentou maior disponibilidade para arborização. No total, o bairro Jardim Primavera apresentou a possibilidade de inclusão de mais 195 árvores. 
Quadro 1. Levantamento do número de mudas que podem ser plantadas nas ruas do bairro Jardim Primavera, Salto de Pirapora-SP.

\begin{tabular}{|l|c|}
\hline \multicolumn{1}{|c|}{ Nome } & Número de mudas \\
\hline Rua Francisco Ortiz & 17 \\
\hline Rua Ovídio B. Leite & 25 \\
\hline Rua Raimundo da Rosa & 38 \\
\hline Rua Ana G. Santos & 24 \\
\hline Rua São Leme dos Santos & 12 \\
\hline Rua Romeu Marcelo & 20 \\
\hline Rua Alexandria M. Conceição & 31 \\
\hline Rua Miguel Andrade & 10 \\
\hline Rua Lauro M. Cesar & 9 \\
\hline Rua Padre Boaventura Manara & 9 \\
\hline Rua Francisco Januário & 19 \\
\hline TOTAL & 214 \\
\hline
\end{tabular}

De modo a facilitar a escolha das espécies passíveis à arborização urbana, foi elaborada uma lista de espécies de pequeno porte para plantio em calçadas estreitas ou com obstáculos para o plantio de espécies maiores (Quadro 2).

Quadro 2. Lista de espécies florestais de pequeno porte para o plantio em caçadas estreitas ou com restrições.

\begin{tabular}{|c|c|c|c|c|c|c|}
\hline \multicolumn{7}{|c|}{ Listagem de espécies de pequeno porte } \\
\hline Nome científico & Nome popular & Família & $\begin{array}{l}\text { Altura } \\
(\mathrm{m})\end{array}$ & Ocorrência & $\begin{array}{l}\text { Diâmetro } \\
\text { do fuste } \\
(\mathrm{cm})\end{array}$ & $\begin{array}{l}\text { Coloração da } \\
\text { florada }\end{array}$ \\
\hline $\begin{array}{l}\text { Aegiphyla sellowiana Cham. } \\
\text { Allophylus edulis (A. St.-Hill., }\end{array}$ & Tamanqueiro & Verbenaceae & $4-7$ & RJ-SP & $20-30$ & Branca \\
\hline Cambess. \& A. Juss.) Radlk. & Chal-chal & Sapindaceae & $6-10$ & AM-RS & $20-30$ & Branca \\
\hline Andira fraxinifolia Benth. & Angelim-doce & Fabaceae & $6-12$ & MA-SP & $30-40$ & Arroxeado \\
\hline $\begin{array}{l}\text { Bauhinia forficata Link } \\
\text { Campomanesia ouazumifolia }\end{array}$ & Pata-de-vaca & Fabaceae & $5-9$ & RJ-RS & $30-40$ & Branca \\
\hline $\begin{array}{l}\text { (Cambess.) O. Berg } \\
\text { Campomanesia phaea (O. Berg) }\end{array}$ & Sete-capotes & Myrtaceae & $6-10$ & RJ-RS & $20-30$ & Branca \\
\hline Landrum & Cambuci & Myrtaceae & $3-5$ & SP-MG & $20-30$ & Branca \\
\hline $\begin{array}{l}\text { Casearia sylvestris } S w . \\
\text { Cyclolobium vecchii A. Samp. Ex }\end{array}$ & Guaçatonga & Flacourtiaceae & $4-6$ & Nacional & $20-30$ & Branca \\
\hline Hoehne & Louveira & Fabaceae & $7-10$ & MG-SP & $30-40$ & Avermelhada \\
\hline Dictyoloma vandellianum A. Juss. & Tingui preto & Rutaceae & $4-7$ & BA-SP & $20-30$ & Amarelada \\
\hline Esenbeckia grandiflora Mart. & $\begin{array}{l}\text { Guaxupita } \\
\text { Cerejeira-do- }\end{array}$ & Rutaceae & $4-7$ & RJ-RS & $20-30$ & Branca \\
\hline $\begin{array}{l}\text { Eugenia involucrata DC. } \\
\text { Hexachlamys edulis (O. Berg) }\end{array}$ & $\begin{array}{l}\text { rio-grande } \\
\text { Pessego do }\end{array}$ & Myrtaceae & $5-8$ & MG-RS & $30-40$ & Branca \\
\hline Kaussel \& D. Legrand & $\begin{array}{l}\text { mato } \\
\text { Algodão do }\end{array}$ & Myrtaceae & $4-6$ & SP-RS & $20-30$ & Branca \\
\hline $\begin{array}{l}\text { Hibiscus pernambucensis Arruda } \\
\text { Inga vera Willd. subsp.affinis }\end{array}$ & brejo & Malvaceae & $3-6$ & RN-RS & $20-30$ & Amarela \\
\hline (DC.) T.D. Penn. & Ingá de brejo & Fabaceae & $5-10$ & SP-RS & $20-30$ & Branca \\
\hline Jacaranda puberula Cham. & Carobinha & Bignoniaceae & $4-7$ & RJ-RS & $30-40$ & Arroxeado \\
\hline Lithraea molleoides (Vell.) Engl. & Aroeira branca & Anarcadiaceae & $6-12$ & MG-RS & $30-40$ & Branca \\
\hline Metrodorea nigra A. St.-Hil. & Caputuna-preta & Rutaceae & $4-5$ & BA-PR & $20-30$ & Vermelha \\
\hline Myrcia selloi (Spreng.) N. Silveira & Cambuí & Myrtaceae & $4-6$ & MG-RS & $20-30$ & Branca \\
\hline $\begin{array}{l}\text { Pera glabrata (Schott) Baill } \\
\text { Rollinia svlvatica (A. St.-Hil.) }\end{array}$ & Tabocuva & Euphorbiaceae & $8-10$ & RJ-SC & $40-50$ & Amarela \\
\hline Mart. & mato & Annonaceae & $6-8$ & PE-RS & $30-40$ & Branca \\
\hline
\end{tabular}


Senna multijuga (Rich.) H.S. Irwin

\& Barneby

Stifftia chrysantha Mikan

Pau-cigarra

Fabaceae

6-10

Nacional

30-40

Amarela

Tabebuia chrysotricha (Mart. ex

A. DC.) Standl.

Diadema

Asteraceae

$3-5$

BA-SP

$15-25$

Amarela

Tibouchina granulosa (Desr.)

Cascudo

Bignoniaceae

4-10

ES-SC

$30-40$

Amarela

Cogn.

Quaresmeira

Melastomataceae

$8-12$

BA-SP

$30-40$

Arroxeada

O Quadro 3 apresenta a lista de espécies florestais de grande porte destinadas ao plantio em calçadas largas ou em praças e espaços abertos.

Quadro 3. Lista de espécies de grande porte para plantio em calçadas largas, espaços abertos ou praças.

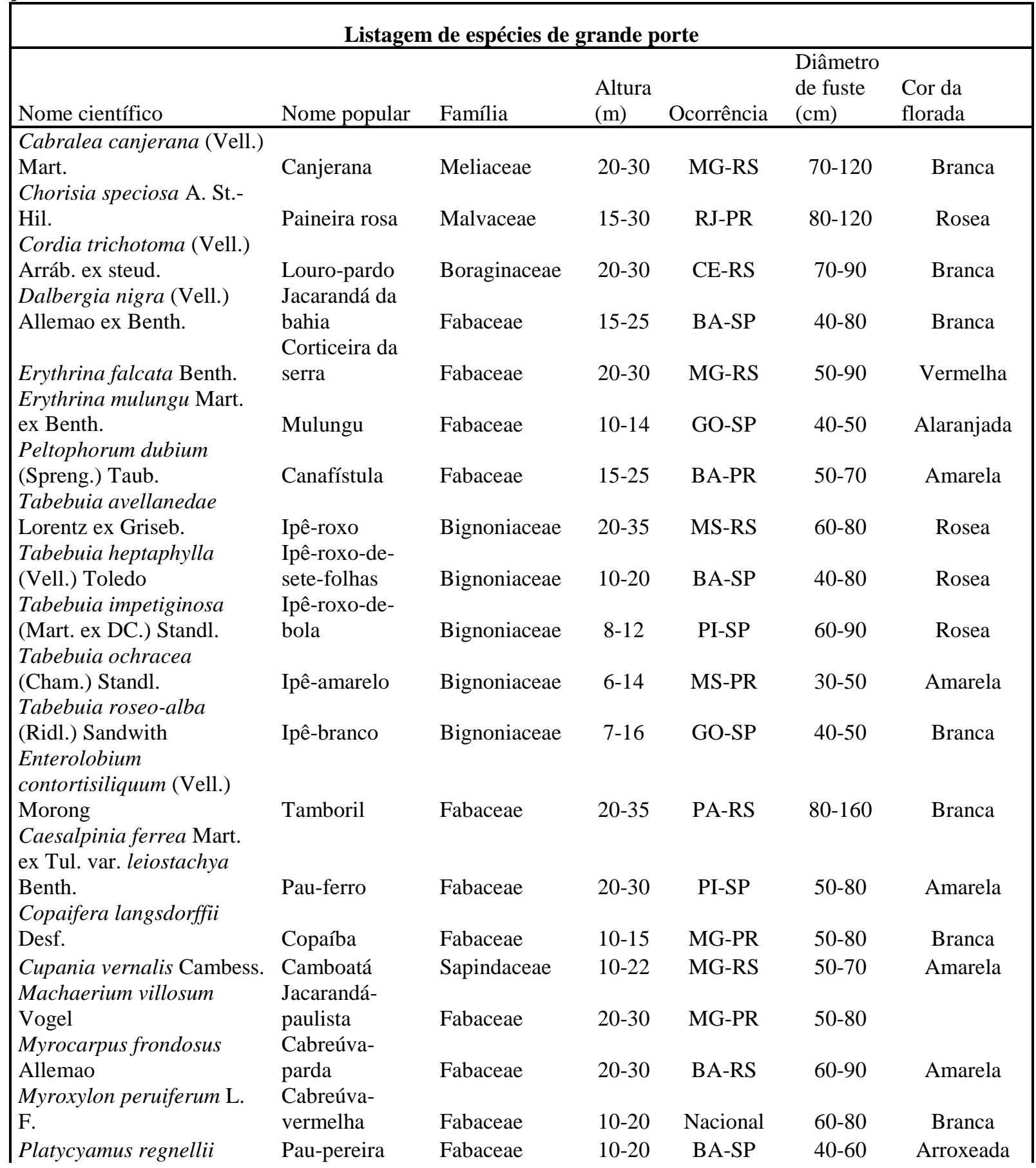


Benth.

Taluma ovata A. St.-Hil.

Pinha-do-brejo

Magnoliaceae

$60-90$

Branca

Vochysia tucanorum Mart. tucano

Vochysiaceae

8-12 MG-SP

$30-40$

Amarela

Cabe salientar que as espécies foram escolhidas de acordo com o bioma Mata Atlântica, sendo este onde o município de Salto de Pirapora está inserido. As espécies são nativas, dando-se preferências para as espécies atrativas à fauna e de distribuição regional.

\subsection{Esquema de plantio}

As mudas deverão ser plantadas fornecendo um espaço mínimo de trânsito ao pedestre nas calçadas de $1,20 \mathrm{~m}$. De acordo com as dimensões das calçadas, as espécies que alcançarem até 4,0 $\mathrm{m}$ de diâmetro de copa, são consideradas de copa pequena, ao passo que deverão ser plantadas em uma área permeável, que possibilite a infiltração de água e a aeração no solo, apresentando cerca de $2,0 \mathrm{~m}^{2}$. As espécies que apresentem valores de diâmetro de copas acima de 4,0 m, deverão ser plantadas em um espaço similar ao anterior, com aproximadamente $3,0 \mathrm{~m}^{2}$. Em locais sob fiação elétrica, ou com calçadas estreitas, foram escolhidas espécies de pequeno porte, com até $5 \mathrm{~m}$ de altura, e com diâmetro de copa de até 4,0 m.

A cova das mudas deve apresentar valores mínimos de $0,6 \mathrm{~m}$ x 0,6 m x 0,6 m. Na situação de passeios com largura inferior a $1,80 \mathrm{~m}$, igual ou maior do que $1,50 \mathrm{~m}$, ela necessita de uma secção retangular de $2 \mathrm{D}$ x 0,6 m quando não houver possibilidade de utilização de grelhas ou pisos drenantes, sendo $\mathrm{D}=(\mathrm{P}-1,20) / 2$, e $\mathrm{P}=$ largura da calçada. $\mathrm{A}$ muda deve estar centralizada, prevendo a manutenção da faixa mínima de passagem de 1,20 $\mathrm{m}$. O posicionamento da muda em passeio público, ao se considerar a largura "P" do mesmo, superior a 1,80 m será admitida uma distância "D", do eixo da árvore até o meio-fio que deverá ser igual a uma vez e meia o raio "R", da circunferência circunscrita à base de seu tronco, quando adulta. $O$ valor " $D$ " não deve ser inferior a $0,30 \mathrm{~m}(\mathrm{D}=1,5 \mathrm{R}$, e $\mathrm{D}$ maior ou igual a 0,30 m) (SVMA-SP, 2005).

Determinadas distâncias devem ser respeitadas conforme o possível, em relação à certos elementos existentes no contexto urbano, descritas nos quadros 4 e 5 .

A altura do tutor deve ser igual ou superior a 2,30 m, enterrado no mínimo 0,60 m em relação ao nível do solo, possuindo a extremidade pontiaguda para uma melhor fixação no solo (SVMA-SP, 2005).

Quadro 4. Distanciamento mínimo em relação aos diferentes elementos existentes em vias públicas:

\begin{tabular}{|l|c|c|}
\hline \multicolumn{1}{|c|}{ Distância mínima de: } & \multicolumn{2}{c|}{ Dimensões da árvore } \\
\hline Esquinas & Pequeno porte & Médio porte \\
\hline Iluminação pública & 5,0 & $*$ \\
\hline Postes & $*$ & 4,0 \\
\hline Placas de identificação e sinalizações & 3,0 & $*$ \\
\hline Hidrantes (gás, água, energia, & 1,0 & 2,0 \\
\hline $\begin{array}{l}\text { Instalações subterrâneas } \\
\text { telecomunicações, esgoto, drenagem) }\end{array}$ & 1,0 & 1,0 \\
\hline Ramais de ligações subterrâneas & 1,0 & 3,0 \\
\hline $\begin{array}{l}\text { Mobiliário urbano (bancas, cabines, guaritas, } \\
\text { telefones) }\end{array}$ & 2,0 & 2,0 \\
\hline Galerias & 1,0 & 1,0 \\
\hline Caixas de inspeção (boca-de-lobo, boca-de-leão, & 2,0 & 2,0 \\
\hline
\end{tabular}




\begin{tabular}{|l|c|c|}
\hline poço-de-visita, bueiros, caixas de passagem) & & \\
\hline Fachadas de edificação & 2,40 & 2,40 \\
\hline Guia rebaixada, gárgula, borda de faixa de pedestre & 1,0 & 2,0 \\
\hline Transformadores & 5,0 & 8,0 \\
\hline Espécies arbóreas & 5,0 & 8,0 \\
\hline
\end{tabular}

Fonte: Manual Técnico de Arborização Urbana (SVMA-SP, 2005).

* As árvores não devem interferir no cone de luz projetado nas ruas pelos postes de iluminação, nem obstruir a visão de placas de identificação e sinalizadores de trânsito que existam no local.

Quadro 5. Distanciamento mínimo de arborização de elementos já existentes em locais públicos livres, como parques, praças e áreas verdes.

\begin{tabular}{|l|c|c|}
\hline \multicolumn{1}{|c|}{ Distância mínima de: } & \multicolumn{2}{c|}{ Dimensões da árvore } \\
\hline Galerias & Pequeno porte & Médio porte \\
\hline Transformadores & 1,0 & 1,0 \\
\hline Caixas de inspeção & 5,0 & 8,0 \\
\hline Guia rebaixada, faixas de travessia & 2,0 & 2,0 \\
\hline Instalações subterrâneas & 1,0 & 2,0 \\
\hline Mobiliário urbano & 1,0 & 1,0 \\
\hline
\end{tabular}

Fonte: Fonte: Manual Técnico de Arborização Urbana (SVMA-SP, 2005).

\section{Participação social}

O envolvimento da comunidade local é sempre uma atividade muito importante para o sucesso do projeto. Geralmente, ocorre a sensibilização dos moradores que acabam adotando o plantio de mudas por longos anos. Este envolvimento poderá ser realizado por meio de educação ambiental, com palestras ministradas por professores e alunos da UFSCar/Sorocaba aos estudantes da escola do bairro, incentivando a participação mas atividades.

\section{Atividades futuras}

\subsection{Pós-plantio}

O acompanhamento do plantio será realizado avaliando-se a fitossanidade e crescimento dos indivíduos. O replantio será feito caso haja morte da muda plantada. As podas serão necessárias caso haja problemas com fiação e/ou iluminação pública, e também, quando houver obstrução da calçada.

\subsection{Segunda fase do projeto}

A segunda fase do projeto consiste-se em recuperar a mata ciliar da nascente do córrego do Jardim Primavera, situado neste mesmo bairro. Para tanto, será feito o levantamento florístico do remanescente arbóreo da mata ciliar existente, a análise da qualidade da nascente e por fim será elaborado um projeto de recuperação da APP de acordo com as espécies florestais encontradas na região. O objetivo dessa segunda etapa é adequar as matas ciliares do município à legislação vigente, que defende uma faixa de mata ciliar de 30 metros nas margens de córregos com até 5 metros de largura, e uma faixa de proteção da nascente de 50 metros de raio, a partir do afloramento superficial (olho d'água) (CONAMA, 2003), estando de acordo, também, com o Plano Diretor do município. 


\section{Cronograma}

O cronograma de atividades, incluindo a etapa de arborização urbana e projeto de recuperação da mata ciliar da nascente do bairro piloto Jardim Primavera, está disposto do seguinte modo:

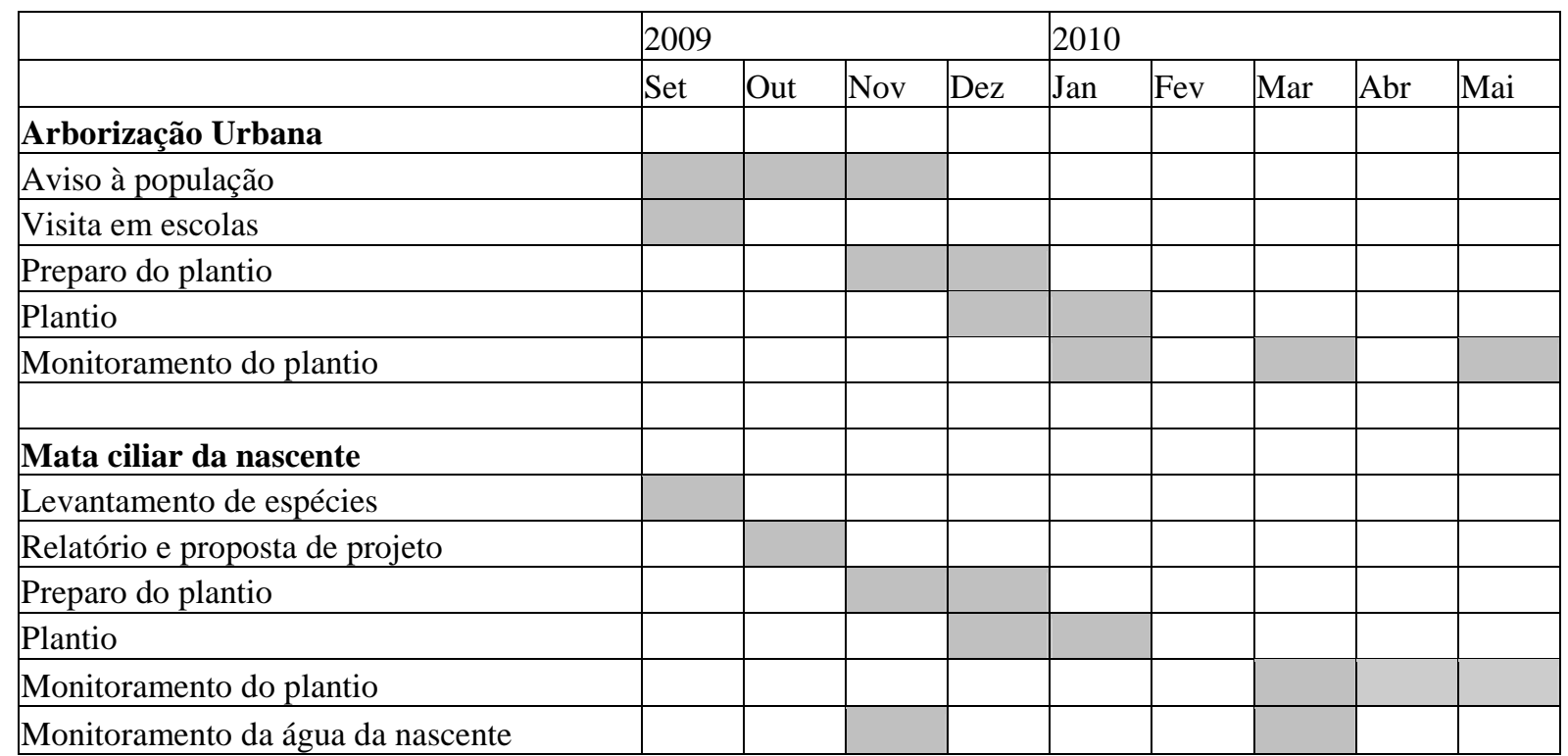

\section{Referências bibliográficas}

Conama. Resolução n.303, de 20 de março de 2002. Dispõe sobre a Área de Preservação Permanente. Diário Oficial da União, Brasília, 13 de maio de 2002. Seção 1, p.68.

Coporusso, D.; Matias, L.F. Áreas verdes urbanas: avaliação e proposta conceitual. In: Simpósio de Pósgraduação em Geografia do Estado de São Paulo, 1, 2008, Rio Claro. Anais eletrônicos...Rio Claro: Universidade Estadual Paulista "Júlio de Mesquita Filho" - Campus Rio Claro, 2008. Disponível em: <http://www.rc.unesp.br/igce/simpgeo/71-87danubia.pdf>. Acesso em: 10 jul. 2009.

Instituto Brasileiro de Geografia e Estatística - IBGE. Cidades. Salto de Pirapora - SP. Brasília, 2009. Disponível em: 〈http://www.ibge.gov.br/cidadesat/topwindow.htm?1>. Acesso em: 17 ago. 2009.

São Paulo (estado). Lei n.13.580/2009, de 24 de julho de 2009. Institui o Programa Permanente de Ampliação das Áreas Verdes Arborizadas Urbanas, e dá outras providências. Diário Oficial, São Paulo, 30 jul. 2009. p.119.

Sbau. Sociedade Brasileira de Arborização Urbana. Boletim Informativo. São Paulo, 2004. 12 p.

Svma-SP. Secretaria do Verde e do Meio Ambiente do Município de São Paulo. Manual Técnico de Arborização Urbana, São Paulo, 2005. p.17-30. 